\title{
A Meta-Review of the Management Development Literature
}

\author{
JOHN CULLEN \\ Irish Management Institute \\ SHARON TURNBULL \\ The Leadership Trust Foundation
}

\begin{abstract}
An appraisal of recent reviews of the literature on management development demonstrates the existence of a number of perspectives on the topic, and this lack of a uniform approach has contributed to confusion about the subject. This article examines a series of recent and existing literature reviews on the topic of management development. It reviews existing and current syntheses of the management development literature and typological models of management development. The aim of the article is to critically analyze these reviews, with the intention of providing an overview of what has been written about management development during the past 25 years. The article unearths core issues and trends that have emerged in the various "literatures" and provides a synthesis of the concepts and paradigms that emerge from these research literatures. The metareview concludes by proposing a framework/model, within which contributions to the literature on management development can be placed.
\end{abstract}

Keywords: management development; executive education; management learning; human resource development

Concerns about the foci and purposes of management and executive education have increasingly been raised with greater regularity (e.g., Ghoshal, 2005; Mintzberg, 2004). The ambiguity surrounding the definition of management development has led to it attracting multiple definitions that do not always align and has caused confusion among both research communities and participants (Lees, 1992; Wexley \& Baldwin, 1986). Storey (1989) suggested that although the literature relevant to management development is growing, it remains disorganized and inchoate. The literature reviews on management development considered in this article demonstrates the existence of a number of perspectives on the topic. This article attempts to address this problem by identifying available reviews of the literature in the field of management development with the aim of providing a framework of how the various perspectives and research approaches to management

Human Resource Development Review Vol. 4, No. 3 September 2005 335-355 DOI: $10.1177 / 1534484305278891$

(C) 2005 Sage Publications 
development have been outlined in the literature. This involves the production of a metadefinition of management development and an outline of the various attempts to differentiate between the various research approaches and praxes, and outlining emerging implications for future research and practice. A metadefinition of management development is offered: management development is a metafield that emerged from a range of disciplines (primarily, though not exclusively psychology, social science, and management studies), which either attempts to frame the reality of management or reframe the reality experienced by managers, with the aim of contributing to the personal resource base of managers and/or the intellectual capital of organizations. This article contributes a model for organizing and understanding existing literature reviews on the topics of management development and education, which provides signposts to additional research avenues. It is suggested that instead of viewing the field of management development research as disorganized and atheorethical, view it as multivocal and theoretically pluralistic.

\section{Purpose}

In seeking to provide a general overview of the very broad topic of management development, relatively recent literature reviews on the subject of management development are examined and evaluated with the aim of identifying the frameworks previously adopted by researchers. Following the description of these reviews in this section, an axis for framing literature on management development is proposed. The reviews examined range from those produced in the mid-1980s to 2002. A literature review conducted by Clement (1981) found little change in the management development evaluation praxis over the 1970s and minimal contributions to the theory of management development in general. The paper unearths issues and trends that have emerged in the various "literatures" and provides a model for understanding the concepts and paradigms that emerge from these research literature. Existing definitions and typologies of management development are explored prior to an examination of available literature reviews, with the aim of establishing a framework for developing a model for appreciating the management development research literature, providing a meta-definition for management development, and identifying further avenues for research.

\section{Definitions}

Because differing epistemological and ontological assumptions exist on the topic of management, definitions of management development and what it is for will be various, discrete, and possibly contradictory. Wexley and Baldwin (1994) point out that "management development may still be one of the most ill-defined and variously interpreted concepts in the manage- 
ment literature" (p. 277). A review of some definitions of, and related to, management development, reported in Table 1, bears this out.

The majority of these definitions have the following in common:

- They view managers as resources and management development is driven by a functional-performance rationale that emphasizes the improvement of management effectiveness, and as a result of this, corporate performance.

- The definitions tend to emphasize that management development is a deliberate and planned activity driven by a strategic orientation.

- Most of the definitions (particularly the earlier ones) view management development as being driven by organizational rather than individual needs.

Only five of the definitions (all offered after 1985) mention the area of learning. The implication of this is that the majority of these definitions present management development as something that is done to managers in order that they might be improved, changed, or developed, rather than appreciating them as individuals with the power to generate meaning or make significant contributions to how learning happens in organizations. The metadefinition of management development offered is one of a metafield that emerged from a range of disciplines (primarily, though not exclusively psychology, social science, and management studies), which either attempts to frame the reality of management, or influences how the reality experienced by managers is reframed, with the aim of contributing to the personal resource base of managers, and/or the intellectual capital of organizations. This metadefinition draws on the definitions presented in Table 1, which largely insist on the role of developmental processes in influencing individual functioning and organizational performance but also takes into account Burgoyne's (1998) definition of the role of managers in creating and maintaining meaning in their organizational contexts.

\section{Typologies of Management Development}

In a review of the rationales adopted by organizations in justifying their investment in management development, Lees (1992) developed a model of 10 different reasons why organizations support and invest in management development. These 10 rationales (described as "faces" by Lees) are: functional-performance, agricultural, functional-defensive, socialization, political reinforcement, organizational inheritance, environmental legitimacy, compensation, psychic defense, and ceremonial.

Although Lees's (1992) model does not highlight the objectives of management development providers or individual participants in programs, it does much to elucidate perspectives on management development from the vista of the purchasing client. Lees's contribution is significant because much of the theory on management development begins with questions about the meaning of management development and what it is for. Long (2004) provides a useful summary of literature that demonstrates how exec- 
TABLE I: Definitions of Management Development

\begin{tabular}{lrc}
\hline Definition & Year & Author \\
\hline $\begin{array}{l}\text { A conscious and systematic decision-action process to } \\
\text { control the development of managerial resources in } \\
\text { the organization for the achievement of organiza- }\end{array}$ & 1975 & $\begin{array}{c}\text { Ashton, Easterby- } \\
\text { Smith, and }\end{array}$ \\
$\begin{array}{l}\text { tional goals and strategies. } \\
\begin{array}{l}\text { An attempt to improve managerial effectiveness } \\
\text { through a planned and deliberate learning } \\
\text { process. }\end{array}\end{array}$ & 1977 & $\begin{array}{c}\text { Irvine } \\
\text { Training Services } \\
\text { Agency (cited in } \\
\text { Mumford, 1997) }\end{array}$
\end{tabular}

... that function which, from deep understanding of business goals and organizational requirements, undertakes the following:

(a) to forecast needs, skill mixes and profiles for many positions and levels;

(b) to design and recommend the professional, career, and personal development programs necessary to ensure competence;

(c) to move from the concept of "management" to the concept of "managing"

A conscious and systematic approach to control the development of managerial resources in the organisation for the achievement of goals and strategies.

... the whole, complex process by which individuals learn, grow, and improve their abilities to perform professional management tasks.

We use the term "management development" to describe management education, structured training and also more informal processes such as mentoring and self-development.

An attempt to improve managerial effectiveness through a planned and deliberate learning process

I define "management development" as the management of managerial careers in an organisational context. I define a "managerial career" as the biography of a person's managerial work life (and I define "managing" as the creation and maintenance of practical meaning in organised activity)

... those processes which engender enhancement of capabilities whilst leaving scope for discretion, creativity and indeterminacy

Management development can be viewed as a process (consisting of planned and unplanned activities and experience) that helps managers in an organisation to develop their experience, ideas, knowledge, skills, relationships, and personal identity, so that they can contribute to the effective development of their organisation.

\author{
1986 Molander \\ 1986 Wexley and \\ Baldwin \\ 1997 Thomson \\ et al. \\ 1987 Mumford \\ 1988 Burgoyne \\ 1989 Storey \\ 1990 Temporal
}


TABLE I (continued)

\begin{tabular}{|c|c|c|}
\hline Definition & Year & Author \\
\hline $\begin{array}{l}\text { "Management development" is a term which embraces } \\
\text { much more than simply education or training. It is } \\
\text { that entire system of corporate activities with the } \\
\text { espoused goal of improving the performance of the } \\
\text { managerial stock in the context of organisational } \\
\text { and environmental change. }\end{array}$ & 1992 & Lees \\
\hline $\begin{array}{l}\text { The complex process by which individuals learn to } \\
\text { perform effectively in managerial roles. }\end{array}$ & 1994 & $\begin{array}{l}\text { Baldwin and } \\
\text { Padgett }\end{array}$ \\
\hline $\begin{array}{l}\text { An attempt to improve managerial effectiveness } \\
\text { through a learning process. }\end{array}$ & 1997 & Mumford \\
\hline $\begin{array}{l}\text { The central challenge of management development is } \\
\text { to control and manage the learning process of man- } \\
\text { agers, focused on individual development and career } \\
\text { success and/or reaching organisational goals. }\end{array}$ & 2001 & $\begin{array}{l}\text { Van der Sluis-den } \\
\text { Dikken and } \\
\text { Hoesksema }\end{array}$ \\
\hline $\begin{array}{l}\text { Management development (MD) is defined as the sys- } \\
\text { tem of personnel practices by which an organisation } \\
\text { tries to guarantee the timely availability of qualified } \\
\text { and motivated employees for its key positions. The } \\
\text { aim of MD is to have at its disposal the right type of } \\
\text { managers and specialists at the right moment }\end{array}$ & 2001 & $\begin{array}{l}\text { Jansen and van } \\
\text { der Velde }\end{array}$ \\
\hline $\begin{array}{l}\text { Management development is . . . a multi-faceted pro- } \\
\text { cess, in which some aspects are easier to identify } \\
\text { and measure than others }\end{array}$ & 2001 & $\begin{array}{l}\text { Thomson, Maybe, } \\
\text { Storey, Gray, } \\
\text { and Iles }\end{array}$ \\
\hline $\begin{array}{l}\text { The definition used for management development ... } \\
\text { includes both the personal and career development } \\
\text { of an individual manager (i.e, attendance at formal } \\
\text { development programmes, seminars, conferences } \\
\text { and also informal learning through methods such as } \\
\text { coaching and mentoring, etc.). It also includes man- } \\
\text { agement education, which is achieved through for- } \\
\text { mal undergraduate/postgraduate qualifications. }\end{array}$ & 2004 & $\begin{array}{l}\text { O’Connor and } \\
\text { Mangan }\end{array}$ \\
\hline $\begin{array}{l}\text {. . We may define appropriate management develop- } \\
\text { ment as a dynamic capability or as a learned pat- } \\
\text { terns of collective activity through which the organi- } \\
\text { zation systematically generates and modifies it } \\
\text { routine in the pursuit of encouraging and developing } \\
\text { managers to balance efficiency and adaptiveness. }\end{array}$ & 2005 & Espedal \\
\hline
\end{tabular}

utive education benefits organizations and executives and conducts an investigation into the personal rationales of individuals for attending university-based executive education programs. Rationales for continual investment by organizations in management development, however, are tacit in nature and an understanding of them remains evasive more than 10 
years after Lees first surfaced it (Paauwe \& Williams, 2001). Lees's (1992) taxonomy of rationales can very broadly be summarized as "resource-based strategies" or as "tools of ideological control." The former refers to approaches that develop managers in order that they might contribute to organizational strategic attainment, and the latter to determining and ordering appropriate managerial behavior in line with the offered political order of the organization.

Lees's (1992) model, however, is not the only one that attempts to somehow develop categorical approaches to understanding the management development "canon." Thomson, Mabey, Storey, Gray, and Iles (2001) outline the main social scientific theories on which management development is based in Table 2 .

The majority of typologies of management development outlined in the literature reviews studied in this article, however, are largely concerned with how management development "happens" in organizational and educational settings. Wohkling (1971) identifies two types of management development: conventional (classroom, case based, etc.) and processual. Another early typology was development by Ashton, Easterby-Smith, and Irvine (1975), which categorized patterns of management development on a matrix that represented visible activity and levels of commitment. Wexley and Baldwin (1986) organize their review under the headings of management education, management training, and on-the-job experiences. Mumford (1997) uncovered three approaches to management development that comprised informal managerial/accidental process, integrated managerial/opportunistic approaches, and formalized development/planned approaches. He also considered piecemeal approaches, which have characteristics similar to the first and third types of management development mentioned. Holman (2000) outlines four types of formal management education as academic liberalism, experiential liberalism, experiential vocationalism, and the experiential/critical school approach. Jansen and van der Velde (2001) comment on previous typologies of management development in a Dutch context, which distinguish between three types of management development: classical management development, which focuses on succession planning; formalized management development and modern management development "in which there is an equilibrium between effective success planning and employee development" (p. 106). They then proceed to develop a typology of management development, which is based on two axes representing the level of attention that management development receives in the contexts of organization and personal development. The four general types of management development they identify are as follows: administrative, derived, partner, and leading management development. 


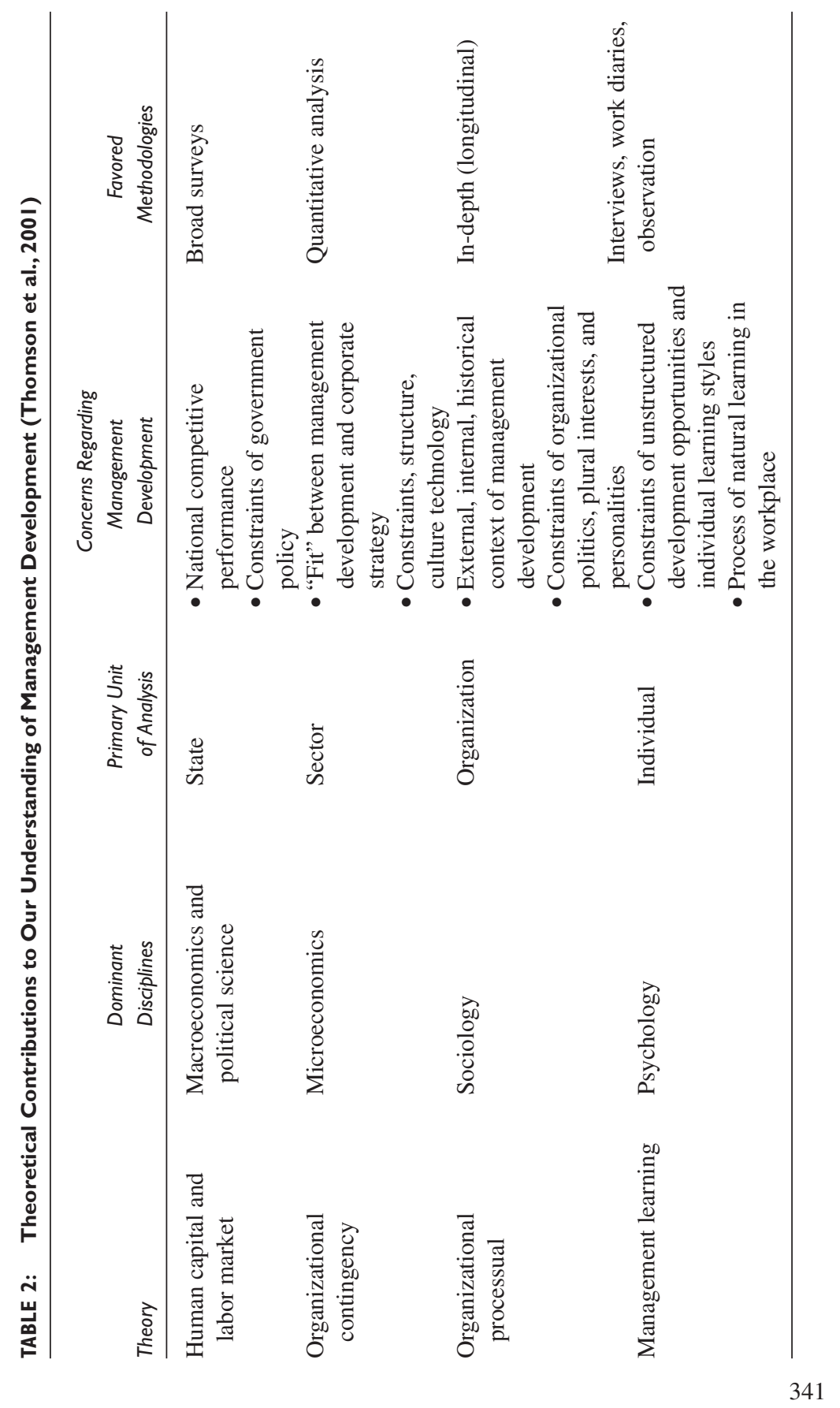


A model that is widely cited in the literature is Burgoyne's (1988) representation of levels of organizational maturity with regard to management development. The model outlines steps that organizations must progress through to gain an appreciation of how management development can grow from having no systematic management development to having strategic development practices that enhance corporate policy formation.

\section{Method}

Initially a search was conducted on "Business Source Premier" under the subject headings: "Management Development," "Executive Education," and "Management Learning," and combined with the term Literature Review. Although a small number of results were uncovered, the literature reviews of the sourced items lead to further references that were not included in the database due to publication type (such as Ashton et al., 1975, and Baldwin and Padgett, 1994). A "trawl" of available issues of journals such as Human Resource Development International, Human Resource Development Review, The Journal of Management Studies, The Journal of Management Development, Management Education and Development, and Management Learning, was also conducted to ensure that key resources were consulted. Items eliminated from the review were those that studied a specific aspect of management development and whose literature review was pertinent to those specific aspects, but did not make a substantial contribution in terms of providing a broader overview of the topic. Similarly, some items that were not written as literature reviews were included on the grounds that they made significant contributions to the project of mapping the management development literature in how they developed theory, supplied frameworks and models, and identified research avenues. In all, nine papers are considered, roughly in the order in which they appeared as some were attempts to appreciate the management development research and practice milieu at a particular point in time. The first four were specifically devised and written as literature reviews on management development, two were written as "compass-setting" reviews, albeit from different perspectives, and the final three discuss management learning.

\section{Management Development Literature Reviews}

\section{Wexley and Baldwin (1986)}

The first review considered here is Wexley and Baldwin's (1986) broad review of pieces published largely after 1980 . They review research under three headings: Management Education is primarily concerned with the 
impact of the competency movement on college or university executive education. Management Training examines work undertaken in the areas of needs assessment, training content and methods, maximizing learning and transfer, evaluation and training for special target groups such as SME managers, entrepreneurs, and international managers. On-the-Job Experiences discusses the action-learning and mentoring as approaches to "structuring and improving the developmental yield of on-the-job managerial experience" (p. 285). They urge greater attention from organizations in both identifying their management development objectives, and evaluating these in the context of their organizational objectives. Recognizing the management development is as multifaceted as "management," they conclude that there is no "one-best-way" for developing managers, and find the activity to be contingent on the management role, the individual and the organizational context.

\section{Storey $(1989,1990)$}

Storey's $(1989,1990)$ two-part review remains one of the extensive available on the subject of management development and is reflective of a growing concern with the topic of management development in British management studies in the 1980s in the light of high-profile reports (for example, Handy, Gordon, Gowe, \& Randlesome, 1988), which had identified the lack of development capabilities in the United Kingdom. Although Storey's $(1989,1990)$ attempt must be appreciated as a paper that synthesized theory that had made a contribution to management research primarily over the course of the 1970s and 1980s it was one of the first to sort through assess the existing imbroglio. From the outset, Storey (1989) reveals a perspective on management development that influences the review: He refers to management development as a "practice and a field of study (it cannot be called a discipline)" (p. 3). This mirror contemporary concerns (Mintzberg, 2004) as to exactly what the construct of "management" is and to the extent to which management should be considered an academic disciplinary area. One of Storey's (1989) central criticisms of the management development literature he reviewed is its tendency to apply universalistic nostrums and to disregard context, both on organizational, and a wider level.

He expresses a concern as to whether management development should be confined to planned interventions or whether it should embrace unplanned and informal ways which managers are made (Storey, 1989, 1990). He differentiates "development" from "training" and "education" and progresses his conceptualization or what management development is in tandem with management development is for. Five objectives for management development are grouped as follows: 
- Organizational change through management development;

- quality improvement, cost reduction, and excellence through management development;

- attitudinal change and value diffusion through management development;

- creating common identities through management development; and

- "stretching" managerial capabilities through management development.

The first objective, which Storey $(1989,1990)$ identifies as having the largest volume of literature attached to it, is similar to Lees's (1992) "functionalperformance" face or rationale, which stresses that the purpose of management development is to directly improve corporate performance and competitiveness through enhanced managerial functioning. Garavan, Barnicle, and O'Suilleabhain (1999) reported an enduring assumption that management development tends to be undertaken from the functional-performance perspective, and noted that very few of the set of alternative assumptions are explored in any significant way. Storey presents three frameworks for management development:

- the "classic approach" treats management development as a system that draws input from the organizational environment in the form of existing plans and diagnoses and generates outputs such as training interventions, succession plans, and related HRM subsystems.

- "contingency" approaches that challenge universalistic templates and identifies key variables that aid the selection of particular management development activities, and

- "alternative conceptualizations" such as management self-development, which is driven by the manager themselves extrinsic to the organizational setting.

These alternative conceptualizations might possibly serve to unearth a contentious area: the possibility that management development activities are interpreted variously at the different levels in which they are engaged. If the bulk of the research literature on management development harbors an assumption that the purpose of management development is to make organizations more competitive by improving management capability, what does this mean for the managers who undergo these programs? Specifically, if management development achieves its aim of improving the capability of managers, are they more likely to then leave their organizational setting and seek out new opportunities where they can better realize their potential, resulting in both the loss of management talent and the organizations investment? If this is true, management development is potentially the opposite of organization development and the rationale of developing the individual manager from the "functional-performance" perspective requires more interrogation. 


\section{Clement (1988)}

Clement's (1988) review of the management development "canon," undertaken around the same time as Storey's $(1989,1990)$, focuses primarily on literature published in the early 1980s. As with Storey, attention is drawn to a large volume of criticism, which had been leveled at both practitioners and researchers in the field of management development in terms of the scarcity of analysis on the outcomes of management development and the appropriateness of management development techniques. In an attempt to evaluate the justification of the criticisms the review unearthed significant changes in the field of management development, which include the trend toward management development in the international realm, the improved design of management development programs, and the improvement of the evaluation of management training programs. From these "positive trends" (p. 46), Clement (1988) distills three keys to effective management development as being: an examination of the cultural variables within which a manager works and an analysis of the nature of the actual management position for which an individual is developed and a consideration of different types of developmental activity.

The first three reviews emphasize the primacy of organizational culture as a context to be considered in management development activities and a need for evaluative research on management development undertaken by organizations. Wexley and Baldwin (1986), Storey (1989), and Clement (1988) all identify shortcomings in the area of evaluation but some improvements in this area during the 1980s were noted with a distinct emphasis on field research and more examinations of improvement in organizational performance and managerial behavior.

\section{Baldwin and Padgett (1994)}

Written from the perspective of psychological researchers, Baldwin and Padgett (1994) review the previous 5 years of literature on the subject. Despite Storey and Clement's (1988) call for context-specific research with a more sociological flavor, Baldwin and Padgett (1994) note significant advances in management development research "in the behavioural specificity of models of effective management and a move toward more empirical work with generalisable samples" (p. 308).

In the initial section on the understanding and assessment of effective management, Baldwin and Padgett (1994) focus on four categories:

- general skill taxonomies,

- assessment instruments and strategies,

- changing managerial environments, and

- specific management populations. 
The second major section of the review, which examines the literature on the contexts of managerial development begins with a statement that the majority of "traditional" research on management development, focuses on research that takes place in structured or formal learning programs. Despite this, Baldwin and Padgett (1993) report on research that cites managers as locating their key learning experiences in informal or on-the-job settings. This section of the review expands on Wexley and Baldwin (1986) and is subdivided into three categories that address this informal development under the headings of job assignments and relationships, and the formal training context.

The third, and final part of the review, looks at emerging issues in management development, which echo concerns stated in the previous reviews to varying extents, concerns raised in the earlier reviews. Three emerging areas are identified: management development as competitive advantage, self-directed management development, and management education in degree granting institutions.

\section{Compass-Setting Reviews}

The remaining five items discussed in this "review of reviews" are not homogenous literature reviews but sections from recent relevant collections that deal with the topic of management development. The first two are the most recent: Thomson et al.'s "Changing Patterns of Management Development" (2001) and Perren and Burgoyne's "Management and Leadership Abilities: An Analysis of Texts, Testimony and Practice" (2002). They are reviewed prior to three contributions to "Management Learning: Integrating Perspectives in Theory and Practice" (Burgoyne \& Reynolds, 1997) as they represent different perspectives on management development to the preceding literature reviews.

"Changing Patterns of Management Development" (Thomson et al., 2001) relies heavily on the UK context and it adopts a largely "macro" view of management development; it is concerned with management development in terms of trends in organizational investment, policies, and quantities. It is concerned with answering questions about the provision of management development, as opposed to questions about meaning, rationales, and assumptions. Its main arguments are based on data collected empirically. These are as follows:

- There has been a growing trend in the amount and significance in management development since the mid-1980s.

- There is a spectrum of organizational management development policies which range from weak to strong.

- "There is broad agreement ... about 'objective' issues such as the amount of training, but there are differences in perception, especially between the organizational view and that of the individual manager, where more 'subjective' issues are concerned" (p. 4). 
The empirical data on which these arguments are based are the results of number of surveys conducted between 1986 and 1997. In addition to the models of management development discussed earlier in this article (see Table 2), an explanation of the British sociohistorical context of management does much to provide indicators as to the national cultural context of management development in the United Kingdom.

"Management and Leadership Abilities" (Perren \& Burgoyne, 2002) addresses an asserted need for providing a framework of management and leadership abilities by reviewing well-known and recent texts and analyzing 93 interviews with a range of parties. A total of 1,013 individual abilities were evoked. Through content analysis, these were condensed to 83 ability sets, and 8 metagroups of abilities: "think strategically; manage and lead people, lead direction and culture, manage self, manage relationships, manage information, manage resources and manage activities and quality" (Perren \& Burgoyne, 2002, p. 5). These are further condensed into three groups: people abilities, thinking abilities, and task abilities. The authors point out that the synthesis represents a mixture of the philosophical and pragmatic and make no claims for completeness. Nevertheless, as a comprehensive review of the literature, combined with qualitative data from a set of research projects, it provides an important contribution to the identification of a framework of abilities to be developed by management education providers.

\section{Management Learning Literature Reviews}

Over the progress of the reviews of the literature reviews that have been discussed so far, there is an interesting change of focus from management development to the topic of management learning. Mentioned in Wexley and Baldwin (1986), it is perhaps most noticeable in Padgett and Baldwin (1994), whose definition of management development was the first among the reviews studied to emphasize learning. The final section of this review of reviews is an examination of three separate papers that, although not ostensibly literature reviews, greatly assist in describing the literature and research that has been conducted in the field of management learning. All three papers were published in "Management Learning: Integrating Perspectives in Theory and Practice" (Burgoyne \& Reynolds, 1997).

\section{Fox (1997)}

In a review that excellently bridges the subjects of management development and education and management learning, Fox (1997) contrasts two leading approaches that have emerged since the 1960s. These approaches are management education (a subset of higher education, which is usually provided by university business and management schools and tends to be 
theoretical) and management development (a subset of human resource development). Fox examines the emergence of management learning and evaluates situated social learning as a concept that highlights the practical and the social and is concerned with how practical and social or "natural learning" occurs in [work] communities. Fox notes that the weight of management education syllabi is tipped to the technical and functional direction, despite this reductionist approach being the subject of criticism by managers. Fox sees the consequences of a set of interrelated cultural and political pressures as central to the emergence of management learning as a new disciplinary area, which is both a subject area and the site of a research community that studies both management education and management development. Management learning's two points of departure are that the education of managers is a different proposition than educating school leavers and that managers learn in many ways outside formal contexts.

Situated social learning theory emerged from ethnographic studies, which explored how individuals are assimilated into communities of practice that are of immediate relevance to their social setting. In this context, formal education belongs to "communities of discourse," which produces "people who are able to talk about practice rather than belonging to a community of practice" (Fox, 1997, p. 30). Fox (1997) states that several management development and education researchers have recognized that considerable amounts of learning occur outside formal learning events and programs and there are very few detailed studies of these "natural" or "everyday" learning processes, partly because they are less easy to investigate than classrooms and other formal settings. The relevance of situated social learning to management learning is that it emphasizes learning processes rather than management developmental and educational processes. Management development and education practitioners are part of a "community of discourse" rather than a "community of practice." Learning by managers in the course of their everyday work is developed as tacit knowledge in communities of practice that exist within organizations but remains a "blind spot" for management development and education practitioners. The implications of this for studying the relationship between management development and education and organizational culture are manifest.

\section{Easterby-Smith and Thorpe (1997)}

Easterby-Smith and Thorpe's (1997) review of dominant research trends in management learning begins with the proposition of a two-dimensional matrix, which represents overlaps between location of management learning (educational or corporate sectors) and dimensions of scale (the "policy" or general level and the "operations" or local level). Easterby-Smith and Thorpe comment that this type of research tends to be an "establishment" 
activity where "researchers act as the handmaids of interest groups and it often seems that personal credibility is more important than mastery of the latest research methods" (p. 42). Their evaluation of corporate development policy focuses on the emergence of competency models that are perceived to be influenced by positivistic methodologies, although social contructionist methodologies are increasingly being applied.

Easterby-Smith and Thorpe (1997) identify three "typical" research areas on operational corporate development: research into corporate training and development, research into "natural" process or learning at work, and research into wider learning processes that occur at systemic and structural organizational levels. Research into the first area tends to focus on new and controversial programs and is generally written from the perspective of a practitioner who implemented an intervention.

Academic researchers have led the inquiry into natural processes of learning, and most of these studies have tended to be of a qualitative nature, but there are also some examples of the usage of quantitative instruments, which are used to analyze individual learning styles and action research methods. Early research on structural and systemic elements of corporate training and development focused on the functional internal elements of management development such as appraisal and career development. Easterby-Smith and Thorpe (1997) report that research since the mid-1980s has attempted to assert a link between investment and corporate performance.

\section{Burgoyne and Jackson (1997)}

Burgoyne and Jackson (1997) describe the Arena Thesis as "an alternative pluralist perspective that views management learning as a domain within which conflicting purposes and values within an organization meet to be reinforced, reconciled or proliferated" (p. 61). Their exploration of the Arena Thesis begins with a description of how management learning has become progressively institutionalized into a field that is dominated by a unitarist perspective. They then explore the origins of the pluralist perspective and compare it to unitarist and radical perspectives. The Arena Thesis is described and specific processes for revitalizing management learning within organizational contexts are presented.

Examining the revitalization of the study of institutionalization theory, Burgoyne and Jackson (1997) report how it reflects the myths of institutional environments rather than demands of the workplace. Finding that training programs have a tendency to become isomorphic as a result of mimetic processes and coercive and normative pressures, Burgoyne and Jackson find it to be a valuable tool for understanding the overwhelmingly unitarist approach to management learning. Although this approach may 
bestow legitimacy on the management development organization or practitioner, it ultimately promotes mediocrity and imitative management practices. Utilizing Morgan's framework of organizational politics, three separate frames of reference for analyzing politics as applied to organizations are presented. The first of these, the "unitary" framework, perceives society as a unitary and homogenous whole and reflects the perspective of traditional organizational theory that represents organizations as cohesive, cooperative systems. The second perspective the "radical" perspective adopts Marxist social philosophy, which views society as consisting of conflicting class interests that produces uneven power relations. The "pluralist" perspective emphasizes diversity and group interests where conflict is viewed as having potential positive outcomes. Burgoyne and Jackson, utilize the metaphors of "parade," "battlefield," and "arena" to respectively characterize these.

The Arena approach to management development goes a long way to meeting concerns that formalized management development raised in a famous antimanagement development Harvard Business Review article. Bowen (1973) advocated an experiential learning approach, "not more theory or classroom training, but an atmosphere in which the managers of the future can make decisions and so gain confidence to make bigger decisions" (p.80).

The arena is the organizational site most suited to management learning and is the locus where nonstandard thoughts are given legitimacy. The result of this is that the arena is also the location where tension exists between being a site where organizational revolutions can be formulated but also where they can be identified and suppressed by parties supportive of unitarist agendas.

The inclusion of Burgoyne and Jackson's (1994) paper on the Arena Thesis in a section purporting to analyze literature reviews might appear incongruous, but it makes a vital contribution to the development of an axis, which is proposed to examine management development and management learning literature. The process of examining literature reviews on management development in a (somewhat) chronological fashion provided opportunities to unearth research needs on management development and to see how these were met by the research community. For example, frustrations with tendencies to apply universalistic nostrums to the development of managers are met with contributions to theory such as the Arena Thesis, and the problem of developing the wider view of the circumstances in which management development can take place (particularly in the context of managers stating that their strongest development experiences took place "on-thejob") is addressed by concepts such as situated social learning, which derive from critical and cultural research approaches. Indeed, issues related to organizational culture emerge frequently and consistently in the context of 
developing managers. The contribution of management learning to management development is highly significant, as the former encapsulates the latter. The study of management learning offers management development and education a language that adequately articulates long-standing dissatisfactions, which in turn generates fresh research agendas. The study of management development, in very general terms, remains part of what Storey (1989) referred to as a practice and a field of study but not a discipline, whereas, according to Burgoyne and Jackson (1997) management learning is "an area of both professional practice and theoretical enquiry" (p. 1).

\section{Discussion}

The following axis is proposed for assessing the literature on management development, education, and learning. Management development research tends to focus on methods and their perceived impacts on organizational contexts. Management learning research adopts a range of theoretical approaches from a variety of disciplines that address that process of learning. In anthropological terms, these are similar to emic and etic perspectives of culture. The research on management development tends to emphasize the relationship of an external management development initiative or event with the aim of instigating some form of change in an organization. Research tends to focus on the material and mechanism of the development initiative, and evidence of change is the goal. The etic pole of the axis thus refers to management development programs or events that are external to the context on which they intervene. Studies on management learning emphasize the "internal life" of the organization and seek to uncover ways in which learning processes can be facilitated within the organization. In Fox's (1997) terms, management learning-centered approaches tend to adopt a low-key approach "which does not try to change corporate cultures until it has first understood them. These approaches work with the grain of the different cultures, within the firm rather than with top-team fantasies" (p. 34).

Another important perspective on this proposed axis for analyzing the management development/learning research literature is the concept of the provision/reception axis. Studies that focus on provision investigate trends in quantities of management development work undertaken in terms of expenditure, time allocated to management training and numbers of individuals with responsibility for management development in an organization. Similar to the policy level in the model for evaluating research proposed by Easterby-Smith and Thorpe (1997), it concentrates on general issues related to management development, usually at national levels. Emic studies focus on reception and tend to focus on how learning processes can be enabled and/or disabled by organizational cultures and/or individuals. They repre- 
TABLE 3: Perspectives for Evaluating Management Development Research

\begin{tabular}{lr} 
Etic & Emic \\
(MD Provision & $\leftarrow$ (ML Reception \\
Perspectives) $\rightarrow$ & Perspectives $)$ \\
\hline
\end{tabular}

sent issues around the organizational cultures and individuals who are the envisaged recipients of the development or education or learning provided by management development providers and practitioners. This proposed axis for evaluating management development and/or learning is represented in Table 3.

Prior to moving away from the assessment of sample literature reviews, it is worth commenting briefly on the presenting research needs from the literature examined thus far. First, Lees (1992) clearly points out that his examination of rationales for management development were not based on data collected empirically. His assessment of the 10 faces of management development asked some important fundamental questions about the reasons why organizations continued to invest in management development. The literature reviews supported his view that there is a significant lacuna in the area of understanding why organizations make this (often substantial) commitment to investing in the development of their managers and perhaps highlights a need for deeper research into these rationales. An inquiry into these rationales might reveal some important "clues" to the relationship between management development and the social and cultural setting in which learning occurs.

Storey (1990) and Clement (1988) highlighted the need for more evaluation of management development practice, primarily from a provision perspective and it would appear that much work has been undertaken in this area since the late 1980s. Both of these reviewers also highlighted the need to research the role organizational contexts in transfer of learning. Baldwin and Padgett's (1994) review noted a weakness in the literature in the area of individual assessment prior to taking part in a management development intervention. They also emphasized a need for research on how managers learn from informal developmental experiences. Fox made a major contribution to this question by outlining the role of situated social learning processes in the development of managers and sounds something of a clarion call for more research in this field.

It is worth considering how recent reviews that attempt to "sort the imbroglio" of management development fit into the proposed axis. Thomson et al.'s (1997) attempt to provide a large and representative picture of management development found that the priority given to management development, and the quantity undertaken had increased significantly. Gra- 
ham, Donoghue, Gray, and Mabey (2000) found that despite a call for the prioritization of management development in Ireland 10 years earlier, it had not undergone a similar revolution in terms of uptake. O'Connor and Mangan (2004) noted that this situation had not radically changed 4 years later, despite an increasing awareness of the importance of management development. These overviews and attempts to address the management development zeitgeist can firmly be located in the etic section of the axis and as of yet the authors know of no attempt to map the research literature on the emic pole.

\section{Conclusion}

It can be seen from these assessments of "where management development is now" that there are a number of perspectives on how far the area has developed. It might even be suggested that instead of viewing the field of management development research as disorganized and atheorethical, that it is multivocal and theoretically pluralistic. Although there appears to be an emphasis on measuring the provision of management development there is also a growing strand that attempts to identify and integrate "natural" management learning with formal education and development initiatives that pay attention to organizational cultural context. The recognition of the existence of various management development, education, and learning literatures suggests that it, as a site, mirrors the diversity of managers and organizations, and their learning requisites. It is hoped that the proposed axis for positioning these literatures might possibly contribute to how future research within the site or field of practice or discipline or theoretical enquiry of management development are appreciated.

This article attempts to sort the imbroglio of management development literature by examining previous attempts to do this. Due to the breadth of the area, a two-pole axis is proposed and it is hoped that it may be considered as a starting point for the development of a more comprehensive model that will assist in developing a detailed map of the known terrain. The most recent systematic and thorough review of the management development literature was Baldwin and Padgett's in 1994 and it would appear that the opportunity presents for another comprehensive review of the literature produced over the past 10 years. This would assess how the field has come and what new concerns, and new voices, have emerged at various points of the continuum modeled, particularly in the context of the growth of the field of management learning. The central research question to arise from this review is related to the model proposed: Is it correct in its assumptions, and if so, can other axes be developed, which will assist us in attempting to appreciate the field, and its future development? 


\section{References}

Ashton, D., Easterby-Smith, M., \& Irvine, C. (1975). Management development: Theory and practice. Bradford, UK: MCB Monographs.

Baldwin, T. T., \& Padgett, M. Y. (1994). Management development: A review and commentary. In C. L. Cooper \& I. T. Robertson (Eds.), Key reviews in managerial psychology (pp. 270-320). Chichester, UK: John Wiley.

Bowen, C. P. (1973). Let's put realism into management development Harvard Business Review, 51, 80-87.

Burgoyne, J. (1988, June). Management development for the individual and the organization. Personnel Management, 40-44.

Burgoyne, J., \& Jackson, B. (1997). The arena thesis: Management development as a pluralistic meeting point. In J. Burgoyne and M. Reynolds (Eds.), Management learning: Integrating perspectives in theory and practice (pp. 54-70). London: Sage.

Burgoyne, J., \& Reynolds, M. (1997). Management learning: Integrating perspectives in theory and practice. London: Sage.

Clement, R. W. (1981, winter). Evaluating the effectiveness of management and training: Progress during the 1970s and prospects for the 1980s. Human Resource Management, 8-13.

Clement, R. W. (1988). Management development in the 1980s: A field in transition. Journal of Management Development, 7, 45-55.

Easterby-Smith, M., \& Thorpe, R. (1997). Research traditions in management learning. In J. Burgoyne \& M. Reynolds (Eds.), Management learning: Integrating perspectives in theory and practice (pp. 38-53). London: Sage.

Espedal, B. (2005). Management development: Using internal or external resources in developing core competence. Human Resource Development Review, 4, 136-158.

Fox, S. (1997). From management education and development to the study of management learning. In J. Burgoyne \& M. Reynolds, M. (Eds.), Management learning: Integrating perspectives in theory and practice (pp. 21-35). London: Sage.

Garavan, T. N., Barnicle, B., \& O'Suilleabhain, F. (1999). Management development: Contemporary trends, issues and strategies. Journal of European Industrial Training, 23, 191-207.

Ghoshal, S. (2005). Bad management theories are destroying good management practices. Academy of Management Learning \& Education, 4, 75-91.

Graham, R. Donoghue, K., Gray, C., \& Mabey, C. (2000). Management development in the republic of Ireland: Patterns \& trends: A review of the main features of management development as practised by large and small companies currently operating in the Republic of Ireland. Dublin: PriceWaterhouseCoopers / Forfás / Open University Business School.

Handy, C., Gordon, C., Gowe, I., \& Randlesome, C. (1988). Making managers. London: Pitman.

Holman, L. (2000). Contemporary models of management education in the UK. Management Learning, 31, 197-207.

Jansen, P., \& van der Welde, M. (2001). A typology of management development. Journal of Management Development, 20, 106-120.

Lees, S. (1992). Ten faces of management development. Management Education and Development, 23, 89-105.

Long, S. F. (2004). Really_Why do executives attend executive education programmes? Journal of Management Development, 23, 701-714.

Mintzberg, H. (2004). Managers not MBAs: A hard look at the soft practice of managing and management development. Upper Saddle River, NJ: Pearson Education.

Mumford, A. (1997). Management development: Strategies for action (3rd ed.). London: Institute of Personnel and Development.

O’Connor, M., \& Mangan, J. (2004). Management development in Ireland. Dublin: Irish Management Institute. 
Paauwe, J., \& Williams, R. (2001). Seven key issues for management development. Journal of Management Development, 20, 90-105.

Perren, L., \& Burgoyne, J. (2002). Management and leadership abilities: An analysis of texts, testimony and practice. London: Council for Excellence in Management and Leadership.

Storey, J. (1989). Management development: A literature review and implications for future research part 1: Conceptualisations and practices. Personnel Review, 18, 3-19.

Storey, J. (1990). Management development: A literature review and implications for future research part 2: Profiles and contexts. Personnel Review, 19, 3-11.

Thomson, A., Storey, J., Mabey, C., Gray, C., Farmer, E., \& Thomson, R. (1997). A portrait of management development. London: Institute of Management.

Thomson, A., Mabey, C., Storey, J., Gray, C., \& Iles, P. (2001). Changing patterns of management development. Oxford, UK: Blackwell.

Wexley, K. N., \& Baldwin, T. T. (1986). Management development. Journal of Management, 12, 277-294.

Wohkling, W. (1971). Management training: Where has it gone wrong? Training and Development Journal, 25, 2-8.

John Cullen is a senior management researcher at the Irish Management Institute's Centre for Management Research, Dublin, Ireland.

Sharon Turnbull, Ph.D., is the deputy research director at the Centre for Leadership Studies, Leadership Trust Foundation, Ross-On-Wye, Herefordshire, UK. 